\title{
HGF derived from cancer-associated fibroblasts promotes vascularization in gastric cancer via PI3K/AKT and ERK1/2 signaling
}

\author{
$\mathrm{XUSHENG} \mathrm{DING}^{1,2^{*}}$, WENQI XI ${ }^{1 *}, \mathrm{JUN} \mathrm{JI}^{2}, \mathrm{QU} \mathrm{CAI}^{2}, \mathrm{JINLING} \mathrm{JIANG}^{1}, \mathrm{MIN} \mathrm{SHI}^{1}$, \\ YINGYAN YU ${ }^{2}$, ZHENGGANG ZHU ${ }^{1,2}$ and JUN ZHANG ${ }^{1,2}$ \\ Departments of ${ }^{1}$ Oncology and ${ }^{2}$ Surgery, Shanghai Institute of Digestive Surgery, Ruijin Hospital, \\ Shanghai Jiaotong University School of Medicine, Shanghai 200025, P.R. China
}

Received February 14, 2018; Accepted June 13, 2018

DOI: $10.3892 /$ or.2018.6500

\begin{abstract}
Cancer-associated fibroblasts (CAFs) are predominate cells in tumor stroma and play a key role in tumor progression. Hepatocyte growth factor (HGF) is a cytokine mainly derived from fibroblasts. In the present study, we reported that HGF significantly promoted angiogenesis of human umbilical vein endothelial cells (HUVECs) and vasculogenic mimicry (VM) formation of gastric cancer cells, respectively, by increasing cell proliferation and migration. In addition, mosaic vessels formed by HUVECs and gastric cancer cells were also increased with treatment of recombinant human HGF and conditioned medium from CAFs. The opposite results were achieved in HGF-neutralized groups. In accordance with these observations, we determined that phosphorylation of AKT and ERK1/2 were upregulated in HUVECs and gastric cancer cells with HGF treatment and co-culture with CAFs. Both AKT inhibitor LY294002 and ERK1/2 inhibitor U0126 reduced the ability of angiogenesis and VM formation, as well as mosaic vessel formation induced by HGF. Gene Set Enrichment Analysis and correlation analysis were performed to confirm our findings. In conclusion, CAF-derived $\mathrm{HGF}$ promotes angiogenesis, VM and mosaic vessel formation via PI3K/AKT and ERK1/2 signaling in gastric cancer and HGF may serve as a potential therapeutic target for cancer anti-vascular treatment.
\end{abstract}

Correspondence to: Professor Jun Zhang, Department of Clinical Oncology, Shanghai Institute of Digestive Surgery, Ruijin Hospital, Shanghai Jiaotong University School of Medicine, 197 Ruijin Er Road, Shanghai 200025, P.R. China

E-mail: junzhang10977@sjtu.edu.cn

*Contributed equally

Key words: cancer-associated fibroblasts, gastric cancer, hepatocyte growth factor, angiogenesis

\section{Introduction}

Gastric cancer (GC) is one of the leading causes of cancer-related deaths worldwide in the past decades $(1,2)$. Despite the improvement of surgical intervention and adjuvant chemotherapy, the 5-year overall survival rate in GC patients is less than $30 \%(3,4)$. Therefore, a better understanding of molecular and cellular mechanisms of GC tumorigenesis and metastasis will assist emergence of preferable therapeutic strategies.

Solid tumors are composed of tumor cells and tumor stroma, including the extracellular matrix (ECM), endothelial cells and a large amount of fibroblasts (5). Following tumorigenesis, local normal fibroblasts are transformed to cancer-associated fibroblasts (CAFs) under the influence of cancer cells (6). CAFs are distinguishable from their normal counterparts with the enhanced expression of alpha-smooth muscle actin ( $\alpha$-SMA) and fibroblast activation protein (FAP). Other markers of CAFs reported are fibroblast specific protein-1 (FSP-1), stromal cell-derived factor-1 (SDF-1) and platelet-derived growth factor receptor- $\alpha$ (PDGFR $\alpha)(7,8)$. Accumulating evidence has indicated a significant role of cytokines secreted by CAFs in mediating tumor growth and metastasis (9-11). Among these stromal cytokines, HGF is expressed mainly in CAFs and acts on c-Met-positive cancer cells in the tumor microenvironment $(12,13)$. Interactions between CAFs and cancer cells activate the $\mathrm{HGF} / \mathrm{c}-$ Met signaling pathway and thus trigger a number of downstream oncogenic signaling cascades, such as PI3K/AKT and ERK1/2, leading to tumor growth and metastasis (14). Recent studies have reiterated the promoting effect of fibroblast-derived HGF on tumor progression and suggest it to be a potential therapeutic target (15-17).

Growth of a solid tumor relies on blood vessels to transport nutrients to satisfy its metabolic demands (18), particularly when the diameter extends beyond $2 \mathrm{~mm}$ (19). Endothelium-dependent vessels are the predominant vascularization in solid tumors and an anti-angiogenesis strategy has been widely used in the treatment of various types of malignant tumors. In addition, as an endothelium-independent pattern, vasculogenic mimicry (VM) tubes formed by cancer cells also participate in vascularization $(20,21)$. VM can serve 
as an internal blood supply network to contribute to tumor progression and has been revealed to be strongly associated with a poor prognosis in gastric cancer $(18,22)$. Mosaic vessels, which are formed by endothelial cells accompanied by tumor cells $(23,24)$, also reveal their significant involvement in tumor growth and metastasis (25). It has been reported that HGF promotes endothelium-dependent angiogenesis in pancreatic cancer and VM formation in hepatocellular carcinoma $(26,27)$, while the specific mechanism has not been well elucidated. In our previous study, we confirmed the existence of VM and mosaic vessels in gastric cancer $(18,28)$. In the present study, we further explored the effects of CAF-derived HGF on angiogenesis, VM and mosaic vessel formation in gastric cancer and illuminate their underlying mechanisms.

\section{Materials and methods}

Cell lines and culture. The human GC cell lines SNU16, MKN74, BGC823, AGS, SGC7901, MGC803 and NCI-N87, and normal GES1 gastric mucosal cells were provided by Shanghai Institute of Digestive Surgery (Shanghai, China). HUVECs were purchased from the Shanghai Institutes for Biological Sciences, Chinese Academy of Sciences (Shanghai, China). These cells were routinely maintained and cultured. Primary cancer-associated fibroblasts (CAFs) were isolated from a GC patient undergoing radical gastrectomy on June 14 in 2017 at the Department of Surgery, Ruijin Hospital, School of Medicine, Shanghai Jiaotong University (29). The patient did not receive preoperative treatment. To maintain the characteristics of primary cells, CAFs passaged for up to 10 population doublings were used in the subsequent experiments. All the cells were cultured at $37^{\circ} \mathrm{C}$ in $5 \% \mathrm{CO}_{2}$ with RPMI-1640 medium (Genom, Hangzhou, China) containing $10 \%$ fetal bovine serum (FBS; Gibco-BRL, Grand Island, NY, USA). The study was approved by the Ruijin Hospital Ethics Committee of Shanghai Jiaotong University School of Medicine and written informed consent was provided by the patient.

Survival analysis with an online database. Survival analysis of 378 GC patients with survival data from TCGA (The Cancer Genome Atlas) database according to HGF expression was performed with online website OncoLnc (http://www.oncolnc. org/) and the lower percentile was set to be equal to the upper percentile. The Kaplan-Meier plotter (http://www.kmplot. com/analysis/) was used to assess the effect of HGF (Affymetrix ID: 209961_s_at, 210755_at, 210997_at, 210998_s_at) on the survival of 876 GC patients from Gene Expression Omnibus (GEO) database and patients were split by auto select best cutoff.

Gene Set Enrichment Analysis (GSEA) and correlation analysis. RNA-seq of 415 patients from Stomach Adenocarcinoma (TCGA, Provisional) was downloaded from cBioPortal platform (http://www.cbioportal.org/). Microarray profiles of $300 \mathrm{GC}$ patients were downloaded from the GEO database (https://www.ncbi.nlm.nih.gov/geo/). Gene Set Enrichment Analysis was performed with GSEA 3.0 software (Broad Institute, Cambridge, MA, USA) and the number of permutations was set to 1,000 . Corresponding gene sets were downloaded from the Molecular Signatures Database v6.1 (http://software.broadinstitute.org/gsea/msigdb/index.jsp). The mean value of gene (containing different Affymetrix IDs) expression was used for correlation analysis.

Immunofluorescence. Briefly, CAFs and frozen sections of GC tissues were fixed in $4 \%$ neutralized formaldehyde followed by permeabilization with $0.5 \%$ Triton X-100 (Sigma-Aldrich; Merck KGaA, Taufkirchen, Germany). Cells and frozen sections were blocked with $3 \%$ bovine serum albumin (BSA) and then incubated at $4^{\circ} \mathrm{C}$ overnight with primary antibodies for $\alpha$-SMA (dilution 1:100; cat. no. ab5694; Abcam, Cambridge, MA, USA), FAP (dilution 1:100; cat. no. sc-71094; Santa Cruz Biotechnology, Santa Cruz, CA, USA) and CD31 (dilution 1:100; cat. no. sc-65260; Santa Cruz Biotechnology). Then, the CAFs and frozen sections were stained with appropriate Alexa dye-conjugated secondary immune reagents and subjected to Olympus BX53 microscope (fluorescence; Olympus Corp., Tokyo, Japan) (magnification, x200) and EVOS ${ }^{\mathrm{TM}}$ FL Color Imaging System (fluorescence; Thermo Fisher Scientific, Inc., Waltham, MA, USA) (magnification, x40), respectively.

ELISA assay. GC cells ( $\left.1 \times 10^{5}\right)$, CAFs $\left(1 \times 10^{5}\right)$ and HUVECs $\left(1 \times 10^{5}\right)$ were cultured in $2 \mathrm{ml}$ of RPMI-1640 complete medium for $36 \mathrm{~h}$. The conditioned medium (CM) was collected and centrifuged at $12,000 \mathrm{xg}$ for $10 \mathrm{~min}$ to remove cell debris. The levels of HGF in supernatants of GC cells, HUVECs and CAFs were detected by ELISA kit (R\&D Systems, Minneapolis, MN, USA) according to the manufacturer's instructions.

Cell proliferation. Cell proliferation was performed using Cell Counting Kit-8 (CCK-8; Dojindo Laboratories, Kumamoto, Japan). MGC803 and HUVECs were suspended in supernatants with different treatments as indicated and plated in a 96-well plate at 1,000 cells/well. Cell proliferation was assessed every $24 \mathrm{~h}$ at an absorbance of $450 \mathrm{~nm}$ using spectrophotometry (BioTek Instruments, Winooski, VT, USA).

Cell migration. MGC803 cells $\left(5 \times 10^{4}\right)$ and HUVECs $\left(5 \times 10^{4}\right)$ suspended in $200 \mu \mathrm{l}$ serum-free RPMI-1640 medium were cultured in the upper chamber with or without CAFs $\left(2 \times 10^{4}\right)$ suspended in $600 \mu \mathrm{l}$ RPMI-1640 medium containing $10 \%$ FBS in the lower chamber for $15 \mathrm{~h}$ using Transwell chambers (8 $\mu \mathrm{m}$; Corning Costar, Corning, NY, USA). Then GC cells and HUVECs were fixed using $4 \%$ neutralized formaldehyde and stained with $0.5 \%$ crystal violet. The migrated cells in the lower chambers were photographed using Olympus BX50 light microscope (Olympus Corp.; magnification, x200) and counted.

Quantitative real-time PCR ( $q R T-P C R)$. Total RNA extracted from cells using TRIzol reagent (Invitrogen; Thermo Fisher Scientific, Inc.) was reversely transcribed to cDNA using a reverse transcription kit (Invitrogen; Thermo Fisher Scientific, Inc.) according to the manufacturer's instructions. Gene expression was quantified by qRT-PCR with SYBR-Green (Applied Biosystems; Thermo Fisher Scientific, Inc.) and ABI Prism 7900HT sequence detection system (Applied Biosystems; Thermo Fisher Scientific, Inc.). The relative mRNA levels were evaluated based on the $\mathrm{Ct}$ values and 
Table I. PCR primers.

\begin{tabular}{lll}
\hline Genes & \multicolumn{1}{c}{ Forward (5'-3') } & \multicolumn{1}{c}{ Reverse (5'-3') } \\
\hline HGF & GGGCTGAAAAGATTGGATCA & TTGTATTGGTGGGTGCTTCA \\
MET & GGTTTTCCTGTGGCTGAAA & GGCATGAACCGTTCTGAGAT \\
MMP1 & GGGGCTTTGATGTACCCTAGC & TGTCACACGCTTTTGGGGTTT \\
MMP2 & GATACCCCTTTGACGGTAAGGA & CCTTCTCCCAAGGTCCATAGC \\
CDH5 & AAGCGTGAGTCGCAAGAATG & TCTCCAGGTTTTCGCCAGTG \\
TFPI2 & TCCTGCCCCTAGACTACGG & CTCCCAGGTGTAGAAATTGTTGG \\
VEGFR2 & GTGATCGGAAATGACACTGGAG & CATGTTGGTCACTAACAGAAGCA \\
GAPDH & ACAACTTTGGTATCGTGGAAGG & GCCATCACGCCACAGTTC
\end{tabular}

GAPDH was used as an internal control. The PCR primers used for the genes in the present study are listed in Table I.

Western blotting. Western blotting was performed as previously described (18). In brief, HUVECs and MGC803 cells were lysed using the RIPA buffer (Thermo Fisher Scientific, Inc.) after stimulation with recombinant human HGF $(50 \mathrm{ng} / \mathrm{ml}$; cat. no. ab105061; Abcam) for $1 \mathrm{~h}$. In groups of inhibition, HUVECs and MGC803 cells were pretreated with LY294002 (50 $\mu \mathrm{M}$; cat. no. 9901) and U0126 (20 $\mu \mathrm{M}$; cat. no. 9903; both from Cell Signaling Technology, Inc., Danvers, MA, USA) for $6 \mathrm{~h}$ before they were co-cultured with primary CAFs for $36 \mathrm{~h}$. Human HGF antibody $(300 \mathrm{ng} / \mathrm{ml}$; cat.no. 24612; R\&D Systems) for neutralization and LY294002 $(50 \mu \mathrm{M}) \mathrm{U} 0126(20 \mu \mathrm{M})$ for inhibition were added into the co-culture system. BCA protein assay kit (Thermo Fisher Scientific, Inc.) was used to calculate the protein concentrations according to the manufacturer's instructions. Protein samples $(20 \mu \mathrm{g})$ were resolved by $10 \%$ SDS-PAGE and then transferred to polyvinylidene fluoride membrane (PVDF; Millipore, Billerica, MA, USA). After blocking with 5\% BSA for $2 \mathrm{~h}$, the membranes were incubated with the primary antibodies for c-Met (1:2,000; cat. no. 8198), ERK1/2 (1:1,000; cat. no. 9102), p-ERK1/2 (1:1,000; cat. no. 9106), AKT $(1: 1,000$; cat. no. 4691) and p-AKT (1:1,000; cat. no. 4060; all from Cell Signaling Technology) and GAPDH (1:1,000; cat. no. sc-47724; Santa Cruz Biotechnology). The protein bands were visualized using chemiluminescence with Pierce ECL Western Blotting Substrate reagents (Thermo Fisher Scientific, Inc.).

Endothelial tube and vasculogenic mimicry formation. A total of $100 \mu 1$ Matrigel (BD Biosciences, San Jose, CA, USA) was added into a 48 -well plate and cultured at $37^{\circ} \mathrm{C}$ in $5 \%$ $\mathrm{CO}_{2}$ to polymerize. HUVECs $\left(2 \times 10^{4}\right)$ and MGC803 cells $\left(4 \times 10^{4}\right)$ were added into plates and cultured in supernatants with different treatments. In groups of inhibition, HUVECs and MGC803 cells were pretreated with LY294002 $(50 \mu \mathrm{M})$ or U0126 $(20 \mu \mathrm{M})$ for $6 \mathrm{~h}$. Following $8 \mathrm{~h}$ of incubation for HUVECs and $24 \mathrm{~h}$ of incubation for MGC803 cells, tubules were photographed using EVOS ${ }^{\mathrm{TM}}$ FL Color Imaging System (light; Thermo Fisher Scientific, Inc.; magnification, x40) and evaluated using Image-Pro Plus software (Media Cybernetics, Rockville, MD, USA).
Mosaic vessel assay. MGC803 cells (2x104) labeled with Dil and HUVECs $\left(2 \times 10^{4}\right)$ labeled with DiO in conditioned medium (CM) with different treatments were added into a 48-well plate coated with $100 \mu 1$ Matrigel (BD Biosciences). In groups of inhibition, HUVECs and MGC803 cells were pretreated with LY294002 $(50 \mu \mathrm{M})$ or U0126 $(20 \mu \mathrm{M})$ for $6 \mathrm{~h}$. Following $24 \mathrm{~h}$ of incubation at $37^{\circ} \mathrm{C}$ with $5 \% \mathrm{CO}_{2}$, tubules were photographed using EVOS ${ }^{\mathrm{TM}}$ FL Color Imaging System (fluorescent; Thermo Fisher Scientific, Inc.; magnification, x40) and evaluated using Image-Pro Plus software (Media Cybernetics).

Statistical analysis. The statistical differences between two groups were analyzed using Student's t-test. Correlation of gene expression between two groups was analyzed using Pearson's correlation coefficient test. All analyses were performed using IBM SPSS 19.0 software (SPSS, Inc., Armonk, NY, USA). All the experiments were performed in triplicate and results were expressed as the mean \pm standard deviation (SD). A two-tailed P-value $\leq 0.05$ was considered to indicate a statistically significant result.

\section{Results}

HGF is mainly derived from CAFs and negatively correlated with OS (overall survival) in GC patients. Primary CAFs were isolated from $\mathrm{GC}$ tissues and immunofluorescence staining was performed to identify spindle-shaped fibroblasts and ascertain the purity of CAFs. As shown in Fig. 1A, both $\alpha$-SMA and FAP proteins were positively expressed and completely overlapped in CAFs. Subsequently, we detected the expression of HGF in normal gastric mucosal cells GES1, GC cell lines (SNU16, MKN74, BGC823, AGS, SGC7901, MGC803 and NCI-N87), primary CAFs and HUVECs. HGF mRNA expression was significantly higher in CAFs than GC cells and HUVECs, while the mRNA expression of MET, a gene regulating the receptor of HGF, was just the opposite (Fig. 1B). The protein levels of HGF and c-Met were also examined and the results were consistent with their mRNA expression (Fig. 1C and D). Therefore, we surmised that HGF mainly originated from CAFs and acted on GC cells and endothelial cells in GC tissues. To further explore the clinical influence of HGF on the OS of GC patients, we analyzed the survival data of 378 GC patients from the TCGA database and $876 \mathrm{GC}$ patients from the GEO database, respectively. As shown in Fig. 1E and F, 
A

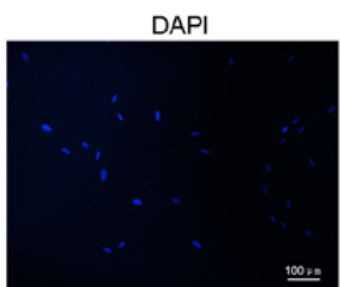

B



E

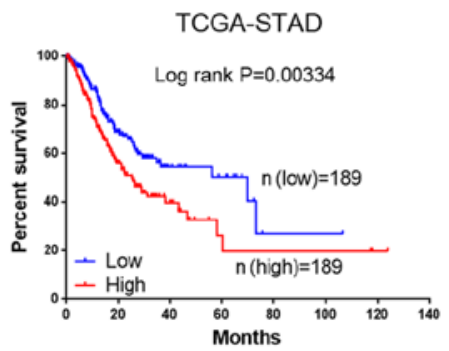

C
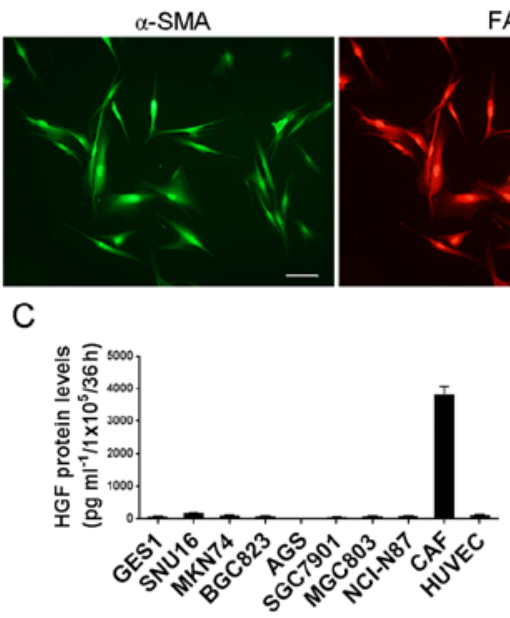

$\mathrm{F}$

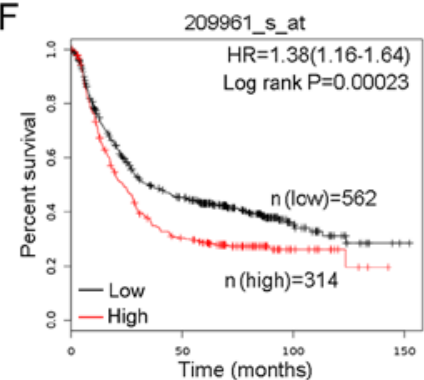

210997_at

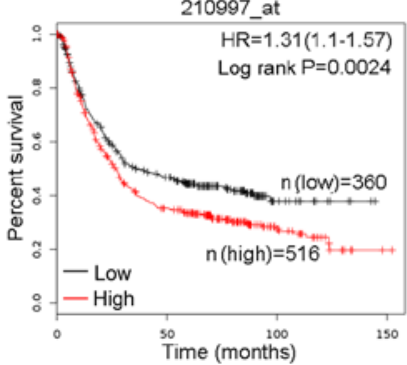

FAP

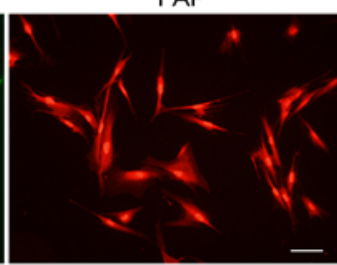

D
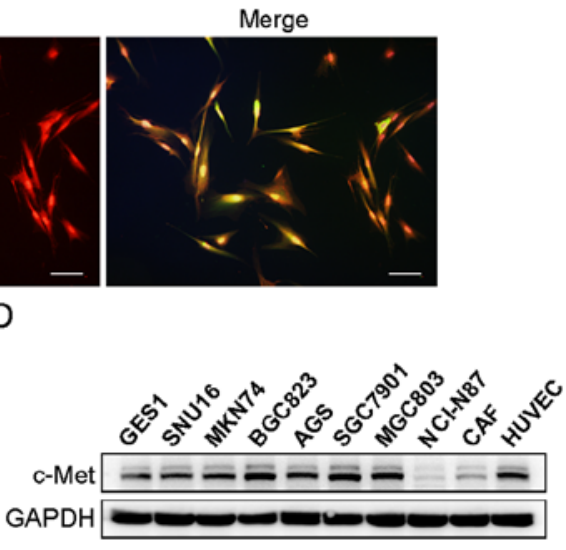

210755_at
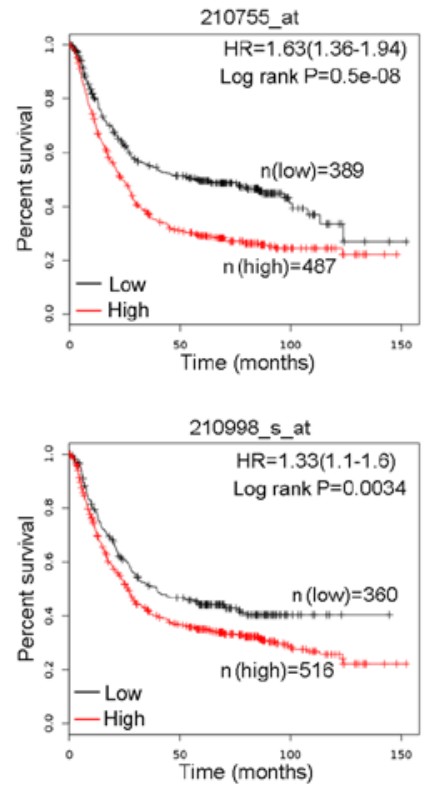

Figure 1. Expression of HGF and its correlation with OS in GC patients. (A) Primary CAFs were identified with $\alpha$-SMA and FAP proteins by immunofluorescence staining. Scale bars, $100 \mu \mathrm{m}$. (B) Relative mRNA expression of HGF and MET in GC cell lines, primary CAFs and HUVECs were assessed by qRT-PCR. (C) HGF protein expression level in GC cell lines, primary CAFs and HUVECs was quantified by ELISA $36 \mathrm{~h}$ after changing the culture medium. (D) The expression level of the c-Met protein in GC cell lines, primary CAFs and HUVECs was examined by western blot analysis. (E) Kaplan-Meier curves of OS according to HGF expression with a TCGA database. (F) Kaplan-Meier curves of OS according to HGF (Affymetrix ID: 209961_s_at, 210755_at, 210997_at, 210998_s_at) expression with a GEO database.

high HGF expression was found to be associated with a worse OS in GC patients. Collectively, this indicated that HGF was predominantly secreted by CAFs and negatively correlated with OS in GC patients.

$C A F$-derived HGF promotes tube formation of HUVECs, VM formation of GC cells and mosaic vessel formation in vitro. Angiogenesis and VM tubes are vital to tumor progression and HGF has exhibited its promoting effects on angiogenesis in pancreatic cancer and VM formation in hepatocellular carcinoma $(26,27,30)$. Therefore, we next examined the effects of HGF on angiogenesis and VM formation in gastric cancer. Conditioned medium (CM) of CAFs with or without HGF neutralization and recombinant human $\mathrm{HGF}$ were subjected to HUVECs and MGC803 cells. Both CAF-CM and recombinant human HGF promoted angiogenesis of HUVECs and VM formation of MGC803 cells, while HGF neutralization significantly suppressed the stimulatory effect of CAF-CM on HUVECs and MGC803 cells (Fig. 2A). These results indicated that CAF-derived HGF promoted angiogenesis and VM formation in gastric cancer.

Tube formation is associated with cell proliferation and migration, thus we evaluated the tumor-promoting ability of HGF. The cell proliferation of HUVECs and MGC803 cells were increased in the CAF-CM groups and decreased in the HGF neutralization groups (Fig. 2B). To better mimic in vivo environments, we build an in vitro co-culture system (Fig. 2C). Migration assays were performed in a co-culture system and the results revealed that both stimulation of recombinant human HGF and co-culture with CAFs increased the ability of cell migration, which was reversed by HGF neutralization (Fig. 2D). The results aforementioned indicated that CAF-derived HGF promoted endothelium-dependent angiogenesis and VM formation by increasing cell proliferation and migration. 

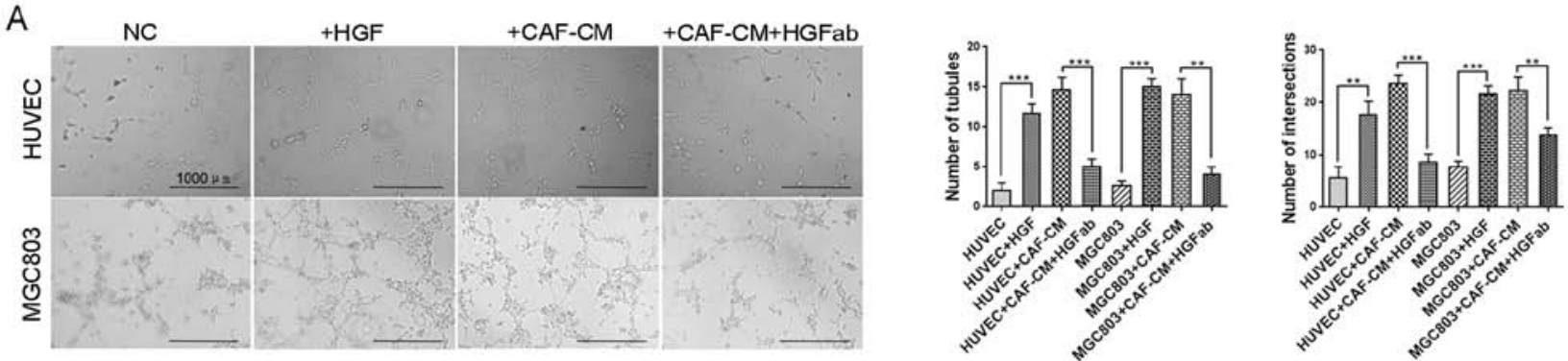

B
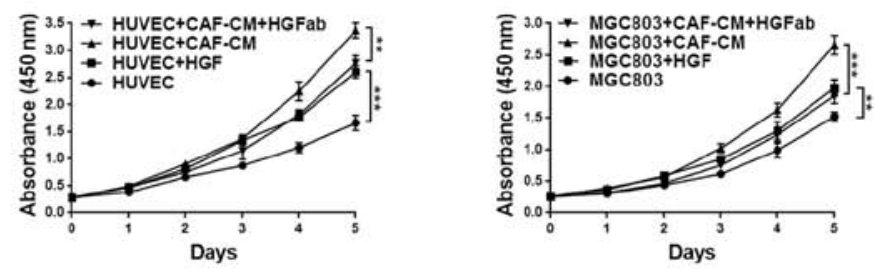

C

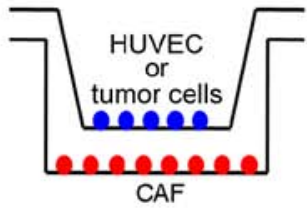

D
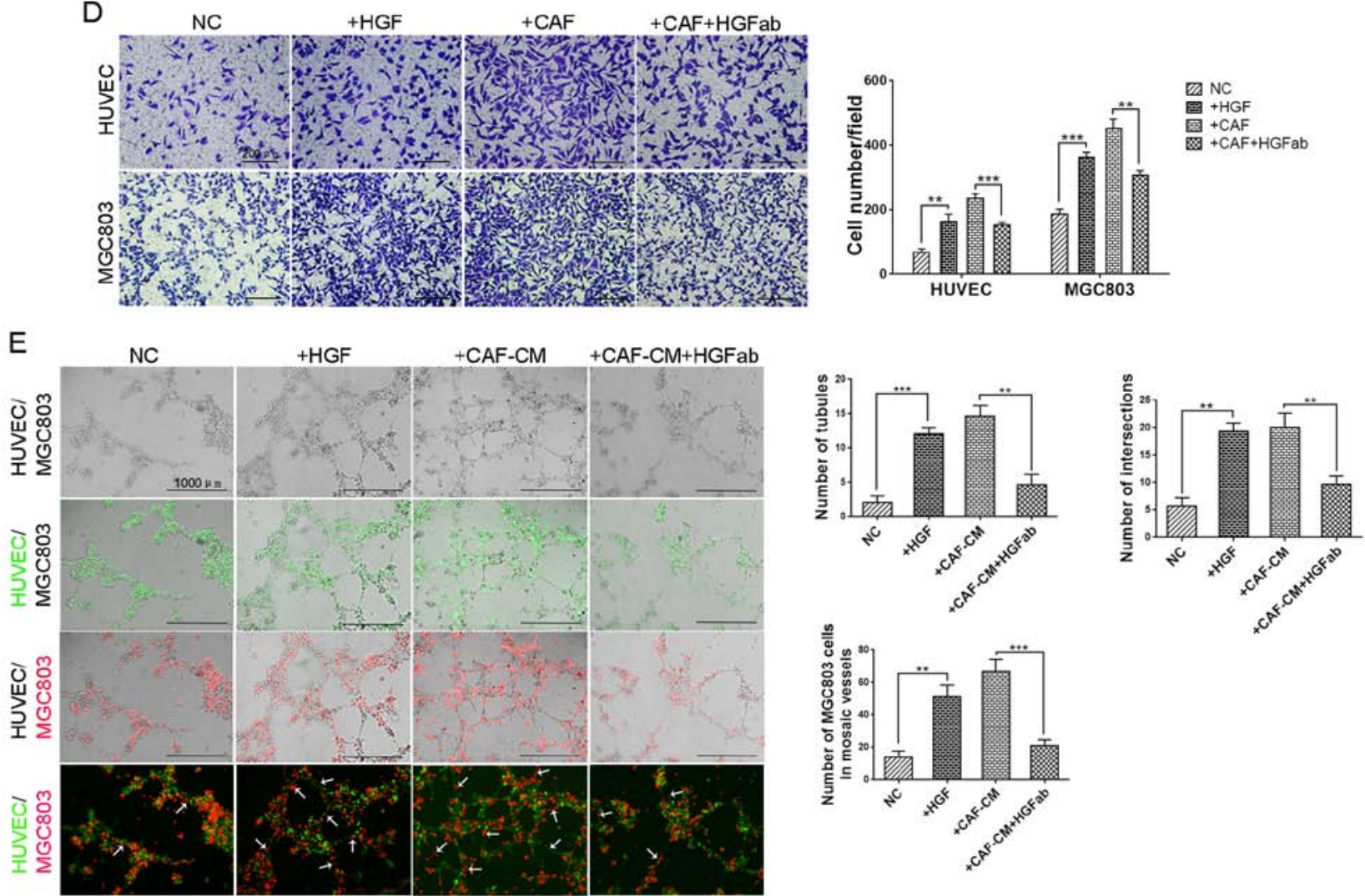

Figure 2. HGF promotes tube angiogenesis, VM formation and mosaic vessel formation. (A) Representative images of angiogenesis and VM with different treatments as indicated. Scale bars, 1,000 $\mu \mathrm{m}$. (B) The proliferation assay of HUVECs and MGC803 cells was performed and assessed by CCK- 8 assay. (C) An in vitro Transwell co-culture system. (D) Migration of HUVECs and MGC803 cells were performed and measured by Transwell assay. Scale bars, $200 \mu \mathrm{m}$ (E) HUVECs labeled with DiO (green) and MGC803 cells labeled with Dil (red) were subjected to mosaic vessel assays. Scale bars, 1,000 $\mu \mathrm{m}$. HGF, $50 \mathrm{ng} / \mathrm{ml}$; HGF neutralizing antibody, $300 \mathrm{ng} / \mathrm{ml} .{ }^{* *} \mathrm{P}<0.01,{ }^{* * *} \mathrm{P}<0.001$.

Mosaic vessels, which are composed of endothelia and cancer cells, serve as a bridge to transfer nutrition during tumor growth. We ascertained the existence of mosaic vessels in gastric cancer in our previous study (28). Since we determined the increase in tubule-forming ability of both HUVECs and GC cells induced by HGF from CAFs, we wondered whether HGF promoted the formation of mosaic vessels. As shown in Fig. 2E, more mosaic vessel structures were observed in groups with treatment of recombinant human HGF and CAF-CM, and the promoting effects were reversed by neutralizing the antibody against HGF. The differences among groups were statistically analyzed and displayed as the number of tubules, number of intersections and number of MGC803 cells in mosaic vessels. These findings indicated that CAFs not only promoted angiogenesis of HUVECs and VM formation of gastric cancer cells, but also increased the number of mosaic vessels in gastric cancer.

HGF from CAFs promotes angiogenesis of HUVECs and VM formation of GC cells via PI3K/AKT and ERK1/2 signaling. 
A

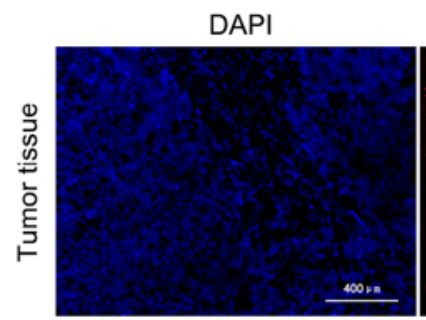

$\alpha$-SMA

CD31
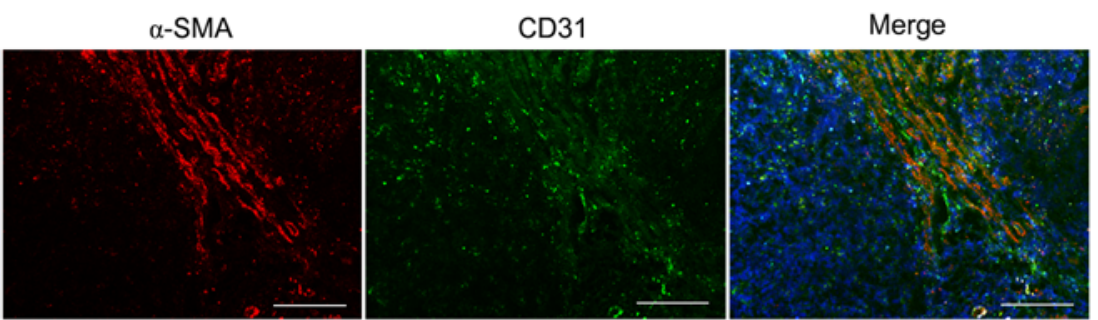

B
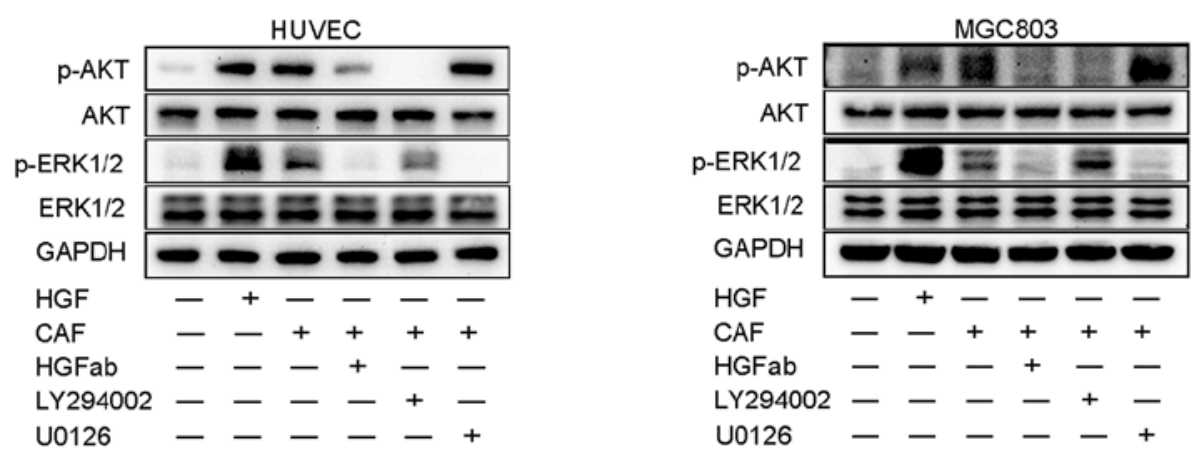

$\mathrm{CAF}-++++$

HGFab ---+-

LY294002 - - - - + -

U0126 - - - - +

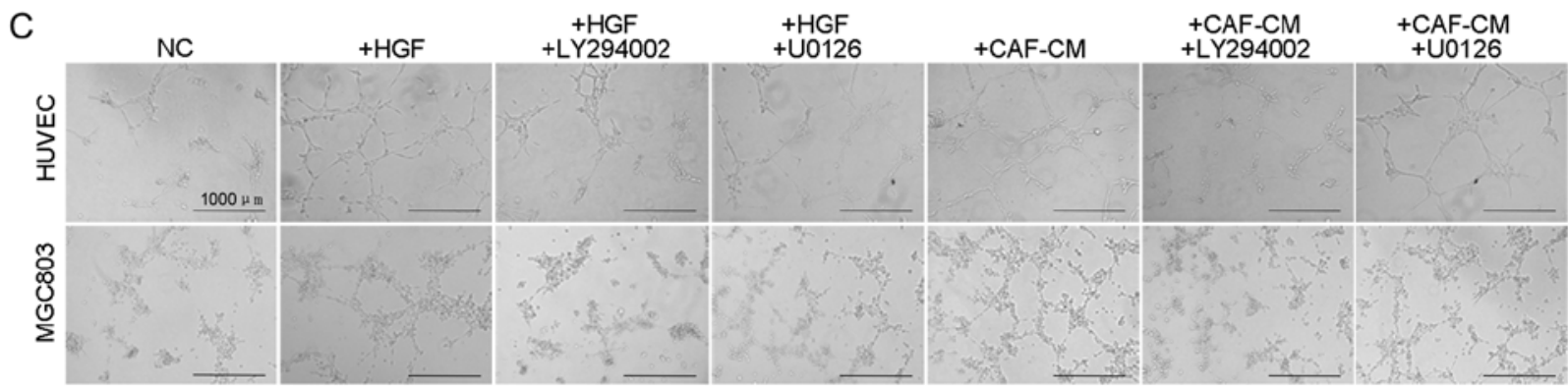

D

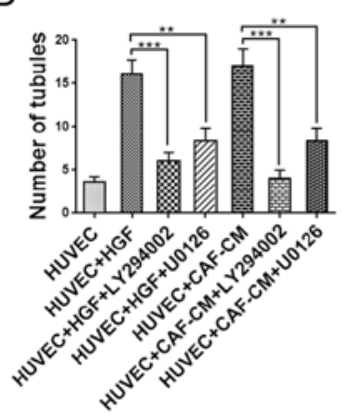

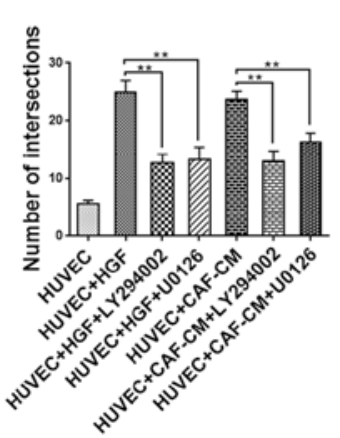

E
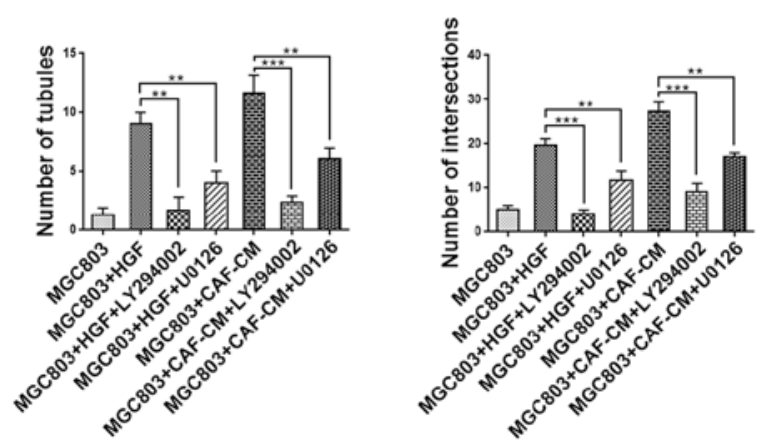

Figure 3. PI3K/AKT and ERK1/2 participate in angiogenesis and VM formation induced by HGF. (A) Representative images of co-localization of $\alpha$-SMA and CD31 in a frozen section of a GC sample. Scale bars, $400 \mu \mathrm{m}$. (B) Downstream oncogenic signals were detected by western blot analysis in HUVECs and MGC803 cells with different treatments as indicated. (C) PI3K/AKT inhibitor LY294002 (50 $\mu \mathrm{M})$ and ERK1/2 inhibitor U0126 (20 $\mu \mathrm{M})$ decreased angiogenesis and VM formation. Scale bars, 1,000 $\mu \mathrm{m}$. Bar charts revealed the number of tubes and intersections of (D) angiogenesis and (E) VM structures. HGF, $50 \mathrm{ng} / \mathrm{ml}$; HGF neutralizing antibody, $300 \mathrm{ng} / \mathrm{ml} .{ }^{* *} \mathrm{P}<0.01,{ }^{* * * *} \mathrm{P}<0.001$.

HGF expression was revealed to be positively correlated with microvessel density (MVD) quantified in gastric and colorectal cancer $(31,32)$. As aforementioned, we demonstrated that HGF was mainly derived from CAFs compared with GC cells and HUVECs. To elucidate the correlation between CAFs infiltration and MVD, co-localization of $\alpha$-SMA and CD31 was performed using frozen sections of GC tissues. As shown in Fig. 3A, CAFs (represented by $\alpha$-SMA) were accompanied by endothelial cells (represented by CD31) to a great degree. This indicated that CAFs infiltration resulted in angiogenesis.

HGF has been revealed to bind to its receptor and then trigger a number of downstream signaling cascades, among which PI3K/AKT and ERK1/2 are associated with tumor angiogenesis and VM formation $(33,34)$. The expression of p-AKT and p-ERK1/2 in HUVECs and MGC803 cells was upregulated with treatment of recombinant human HGF as well as in a co-culture system with CAFs, which was reversed by HGF neutralization (Fig. 3B). To determine whether CAF-derived HGF promoted angiogenesis and VM formation through PI3K/AKT and ERK1/2 signaling, the inhibitor of PI3K/AKT signaling, LY294002, and inhibitor of ERK1/2 signaling, U0126, were used to investigate the underlying mechanisms. As shown in Fig. 3C, the promoting effects of recombinant human HGF and CAF-CM on angiogenesis of HUVECs and 
A

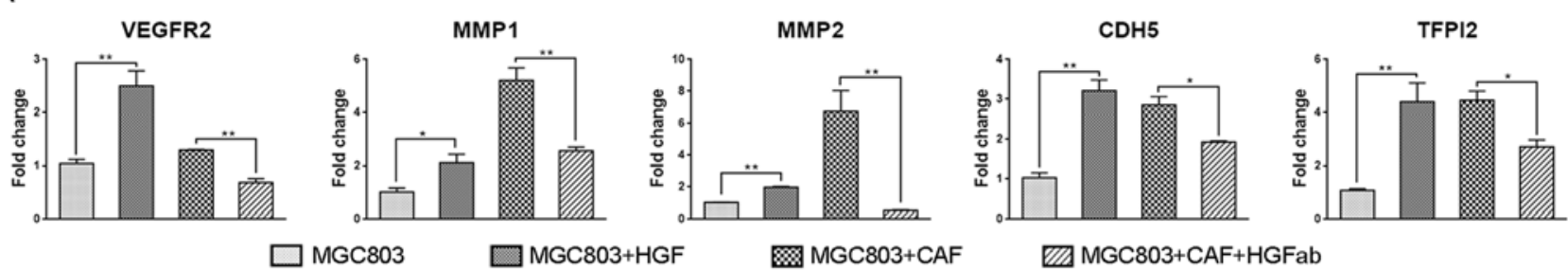

B

$\operatorname{TCGA}(n=415)$
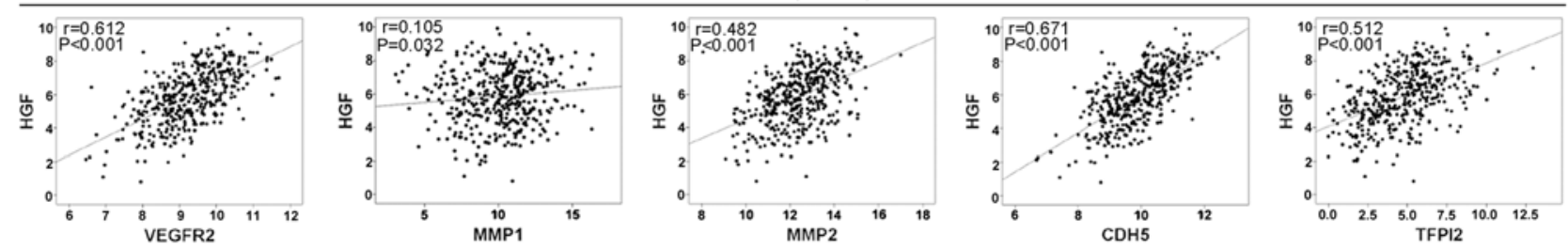

GSE62254 $(n=300)$
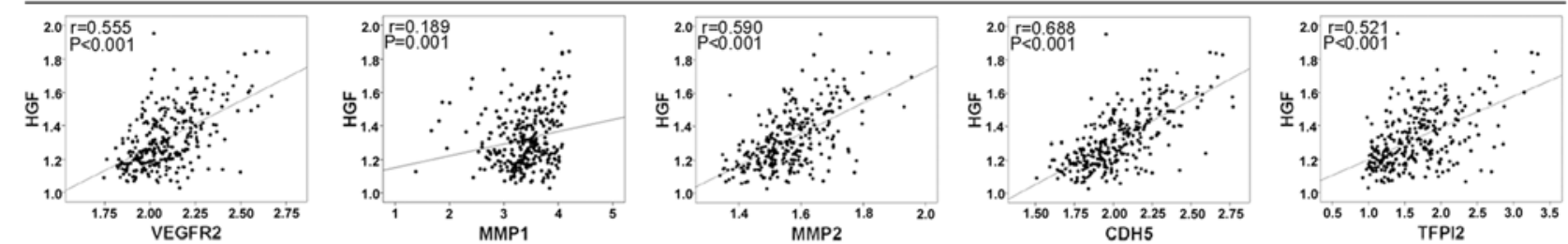

C

D
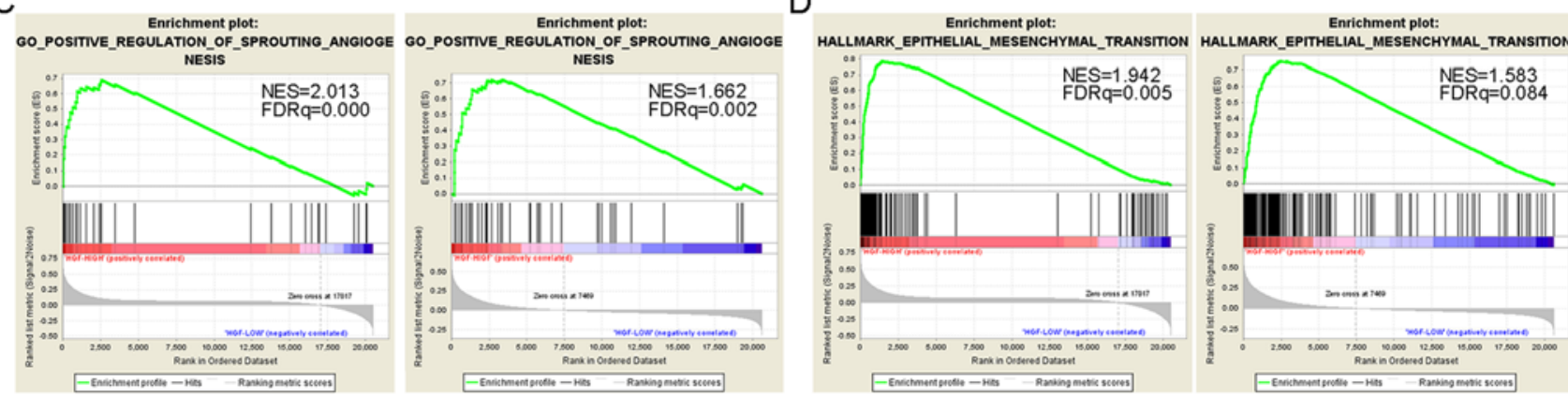

Figure 4. Correlation analysis and gene set enrichment analysis (GSEA). (A) Expression of angiogenesis-promoting related gene, VEGFR2 and VM-promoting related genes, MMP1, MMP2, CDH5 and TFPI2, were assessed by qRT-PCR. (B) Positive correlation between HGF and angiogenesis-promoting and VM-promoting related genes were analyzed with databases of TCGA and GSE62254, respectively. (C) GSEA results of angiogenesis with the TCGA (left panel) database and the GSE62254 (right panel) database. (D) GSEA results of epithelial-mesenchymal transition with the TCGA (left panel) database and the GSE62254 (right panel) database. Each bar corresponded to one gene. HGF, $50 \mathrm{ng} / \mathrm{ml}$; HGF neutralizing antibody, $300 \mathrm{ng} / \mathrm{ml} .{ }^{*} \mathrm{P}<0.05,{ }^{* *} \mathrm{P}<0.01$.

VM formation of MGC803 cells were significantly inhibited by LY294002 and U0126, respectively. Statistical analysis of the number of tubules and number of intersections among these groups confirmed the results (Fig. 3D and E). This indicated that both PI3K/AKT and ERK1/2 signaling participated in angiogenesis and VM formation induced by HGF in gastric cancer.

Multiple molecules have been reported to participate in angiogenesis and VM formation $(21,35)$. To confirm the promoting effects of HGF on angiogenesis and VM formation and explore the underlying mechanisms, we investigated and determined that HGF could regulate the expression of angiogenesis-related gene, VEGFR2 and VM-promoting related genes, MMP1, MMP2, CDH5 (VE-cadherin) and TFPI2. As shown in Fig. 4A, these genes were upregulated in MGC803 cells with treatment of recombinant human HGF and co-culture with CAFs compared with the negative control and HGF neutralized groups, respectively. Moreover, we analyzed gene expression patterns using RNA-seq of 415 GC patients from the TCGA database and microarray profiles of 300 GC patients from the GSE62254 database, and found that HGF was positively correlated with these molecules, respectively (Fig. 4B). The correlation between HGF and angiogenesis was also analyzed by Gene Set Enrichment Analysis (GSEA) with the TCGA and GSE62254 databases, and the results revealed that genes positively correlated with angiogenesis were enriched in HGF-high expression samples (Fig. 4C). Increasing evidence has indicated that epithelial-mesenchymal transition (EMT) could induce VM formation $(36,37)$, thus, we subsequently explored the relationship between HGF and EMT by GSEA and found that genes positively correlated with EMT were also enriched in HGF-high expression samples (Fig. 4D). In conclusion, CAF-derived HGF promoted angiogenesis and VM formation via PI3K/AKT and ERK1/2 signaling and upregulated the expression of these processes-related genes in gastric cancer. 


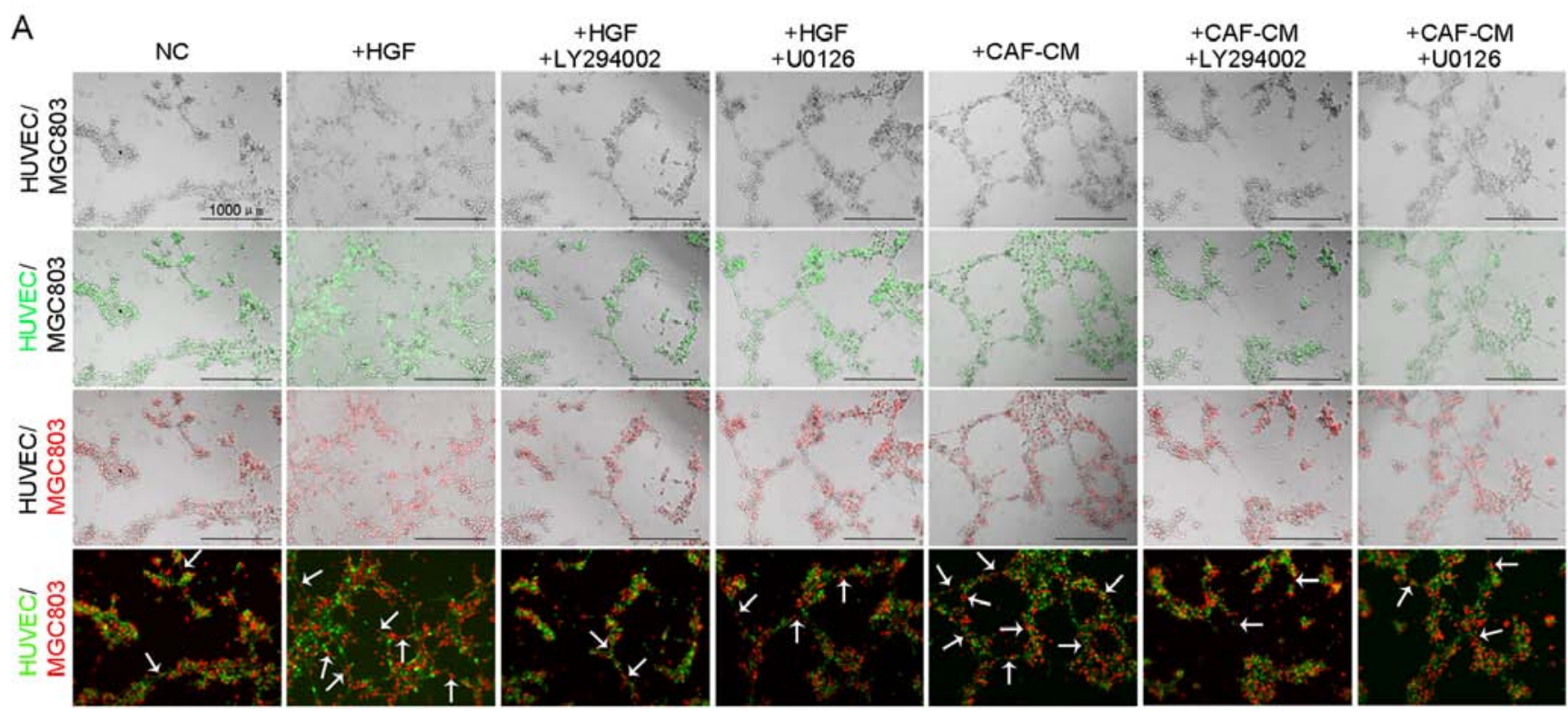

B

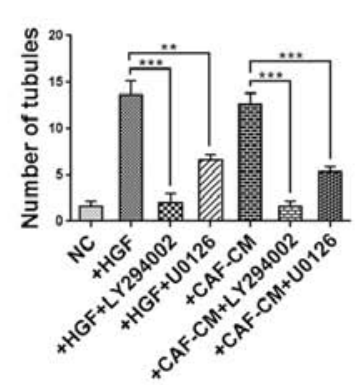

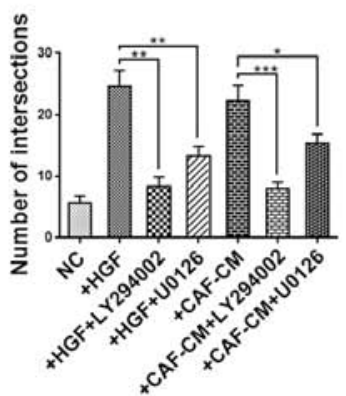

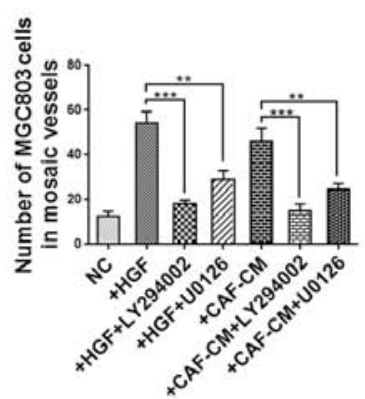

Figure 5. PI3K/AKT and ERK1/2 participate in mosaic vessel formation induced by HGF. (A) Representative images of mosaic vessels with different treatments as indicated. HUVECs labeled with DiO (green) and MGC803 cells labeled with Dil (red). HGF, $50 \mathrm{ng} / \mathrm{ml}$; LY294002, $50 \mu \mathrm{M}$; U0126, $20 \mu \mathrm{M}$. Scale bars, $1,000 \mu \mathrm{m}$. (B) Bar charts displaying the number of tubules, the number of intersections and the number of MGC803 cells in mosaic vessels between different groups. ${ }^{*} \mathrm{P}<0.05,{ }^{* *} \mathrm{P}<0.01,{ }^{* * *} \mathrm{P}<0.001$.

Inhibitors of PI3K/AKT and ERK1/2 signaling reduce mosaic vessels induced by CAF-derived HGF. Mosaic vessels are formed by the cooperation of endothelia and cancer cells. Since we demonstrated the inhibiting effects of LY294002 and U0126 on both angiogenesis of HUVECs and VM formation of GC cells, we next examined whether these inhibitors had the same influence on mosaic vessel formation. As shown in Fig. 5A, both recombinant human HGF and conditioned medium of CAFs increased the number of mosaic vessels, which was reversed by inhibition of PI3K/AKT and ERK1/2 signaling. The number of tubules, number of intersections and number of MGC803 cells in mosaic vessels in the CAF-CM group were significantly increased compared with the control groups and significantly decreased when treated with LY294002 and U0126 (Fig. 5B). These results indicated that CAF-derived HGF promotes mosaic vessel formation via both PI3K/AKT and ERK1/2 signaling.

\section{Discussion}

Cancer-associated fibroblasts have revealed their irreplaceable roles in maintaining malignancy of solid tumors through secreting various types of cytokines, among which HGF has been reported to facilitate tumorigenesis and tumor progression $(17,38)$. HGF overexpression was revealed to be positively correlated with depth of invasion, lymph node metastasis, TNM stage and poor survival of patients with gastric cancer (39). We analyzed the survival data of GC patients from TCGA and GEO databases and confirmed the negative correlation between HGF expression and overall survival. In the present study, we determined that HGF originating from CAFs accelerated endothelium-dependent angiogenesis through promotion of HUVEC proliferation and migration, which was consistent with a previous study in pancreatic cancer (26). In a co-culture system, the migration ability of GC cells was enhanced through reciprocal interactions with CAFs, which, however, was inhibited by neutralizing antibody against HGF. Thus, we demonstrated that CAF-derived HGF also facilitated VM formation. Mosaic vessels are formed by both endothelia and cancer cells. Given that HGF increased the abilities of both HUVECs and MGC803 cell migration, we further investigated and confirmed the promoting effect of CAF-derived HGF on mosaic vessel formation. These results revealed that $\mathrm{HGF}$ promotes vascularization, namely angiogenesis, VM formation and mosaic vessel formation. Thus, it is reasonable to hypothesize that HGF derived from CAFs may facilitate tumor progression through promotion of angiogenesis, VM formation and mosaic vessel formation in the GC microenvironment. 
As one of the hallmarks of cancer, tumor angiogenesis is positively correlated with tumorigenesis, tumor growth and metastasis, which has been demonstrated by an increasing number of studies $(30,40)$. An anti-angiogenesis strategy has been applied to inhibit tumor progression in multiple types of cancers (41-43). However, cancer cells could evade inhibition of angiogenesis after an initial response to therapeutic strategies that target endothelial cells. Thus, vasculogenic mimicry, a cancer cell-dependent pattern associated with poor survival, has become a potential target for anticancer strategy (44). HGF exhibits its tumor-promoting effect through binding to its receptor, c-Met, and then triggering several oncogenic signaling cascades, among which $\mathrm{PI} 3 \mathrm{~K} / \mathrm{AKT}$ and ERK1/2 signaling have been reported to regulate angiogenesis and VM formation $(21,33,34)$. PI3K/AKT and ERK1/2 signaling pathways have been revealed to regulate the growth, survival, and migration of endothelial cells and thus promote angiogenesis (45). Suppressing the phosphorylation of VEGFR2 could reduce the activation of the PI3K/AKT and ERK1/2 signaling pathways and thus inhibit angiogenesis (46). ERK1/2 was revealed to be positively involved in hypoxia-induced VM formation (47), and PI3K/AKT inhibition suppressed VM formation capacity of hepatocellular carcinoma cells (48). HGF has been reported to promote angiogenesis in pancreatic cancer and VM formation in hepatocellular carcinoma $(26,27)$, and in the present study, we found the same effects of HGF in gastric cancer. To further investigate whether the promoting effects of HGF on angiogenesis and VM formation rely on PI3K/AKT and ERK1/2 signaling, specific inhibitors of the two signaling pathways were subjected to the following experiments. Both inhibition of PI3K/AKT and ERK1/2 signaling could decrease the tubule-like structures of angiogenesis induced by HUVECs and VM induced by MGC803 cells. Many genes have been reported to facilitate VM formation $(33,34,49)$. In addition, we found that HGF increased the expression of VM-promoting genes, such as MMP1, MMP2, CDH5 (VE-cadherin) and TFPI2 in GC cells, which were confirmed by correlation analysis of 415 samples from the TCGA database and 300 samples from the GSE62254 database. Other molecules that could increase VM formation, such as MMP9, MT1-MMP and EphA2 were also positively correlated with HGF by correlation analysis using these databases. However, they were not upregulated in groups with stimulation of HGF (data not shown). Thus, we hypothesized that HGF could facilitate VM formation through, at least in part, upregulation of the expression of these VM-promoting genes. Given these results, we examined the influence of LY294002 and U0126 on mosaic vessel formation, and found that they both significantly decreased the number of mosaic vessels. These findings suggest that PI3K/AKT and ERK1/2 signaling also participate in mosaic vessel formation. In addition, there are some instructive points that warrant improvement in our experiments: i) in vivo experiments investigating the impact of CAF-derived HGF on angiogenesis, VM formation and mosaic vessel formation should be conducted; and ii) the characteristics of CAFs may be influenced by clinical features, like TNM stage, pathological type and status of HP infection, thus CAFs isolated from different pathological types, tumor stages, and HP infection status should be analyzed. Fortunately, both these aforementioned points will be addressed in our ongoing follow-up studies.

Collectively, CAF-secreted HGF promoted angiogenesis, $\mathrm{VM}$ formation and mosaic vessel formation in gastric cancer. Crosstalks between CAFs and HUVECs, as well as gastric cancer cells promoted HUVEC and gastric cancer cell migration, and thus accelerated the process of vascularization. However, these effects could be inhibited by suppressing $\mathrm{PI} 3 \mathrm{~K} / \mathrm{AKT}$ and ERK1/2 signaling. These results indicated that CAF-derived HGF promotes vascularization via PI3K/AKT and ERK1/2 signaling in gastric cancer, and it may serve as a prognostic indicator and potential therapeutic target for cancer anti-vascular treatment.

\section{Acknowledgements}

Not applicable.

\section{Funding}

The present study was supported by the National Science Foundation of China (nos. 81672327, 81502013 and 81602411), the Program of Shanghai Academic/Technology Research Leader (no. 17XD1402600), the Program for Outstanding Medical Academic Leader and Shanghai Municipal Education Commission-Gaofeng Clinical Medicine Grant Support (no. 20161410), the Development Grant for Clinical Trial (no. SHDC12017X06), the SCORE Foundation (no. Y-MX2015-078) and the Shanghai Municipal Commission of Health and Family Planning (no. 20154Y496).

\section{Availability of data and materials}

The datasets used during the present study are available from the corresponding author upon reasonable request.

\section{Authors' contributions}

XSD, WQX and JZ conceived and designed the study. XSD, WQX, JJ and QC performed the experiments. XSD, WQX, JLJ and MS wrote the manuscript. YYY, ZGZ and JZ reviewed and edited the manuscript. All authors read and approved the manuscript and agree to be accountable for all aspects of the research in ensuring that the accuracy or integrity of any part of the work are appropriately investigated and resolved.

\section{Ethics approval and consent to participate}

The study was approved by the Ruijin Hospital Ethics Committee of Shanghai Jiaotong University School of Medicine and written informed consent was provided by the patient.

\section{Patient consent for publication}

Not applicable.

\section{Competing interests}

The authors state that they have no competing interests. 


\section{References}

1. Ferro A, Peleteiro B, Malvezzi M, Bosetti C, Bertuccio P, Levi F, Negri E, La Vecchia C and Lunet N: Worldwide trends in gastric cancer mortality (1980-2011), with predictions to 2015, and incidence by subtype. Eur J Cancer 50: 1330-1344, 2014.

2. Bertuccio P, Chatenoud L, Levi F, Praud D, Ferlay J, Negri E, Malvezzi M and La Vecchia C: Recent patterns in gastric cancer: A global overview. Int J Cancer 125: 666-673, 2009.

3. Son $T$ and Hyung WJ: Laparoscopic gastric cancer surgery: Current evidence and future perspectives. World J Gastroenterol 22: 727-735, 2016.

4. Xu W, Beeharry MK, Liu W, Yan M and Zhu Z: Preoperative chemotherapy for gastric cancer: Personal interventions and precision medicine. Biomed Res Int 2016: 3923585, 2016.

5. Bhowmick NA, Neilson EG and Moses HL: Stromal fibroblasts in cancer initiation and progression. Nature 432: 332-337, 2004.

6. Erez N, Truitt M, Olson P, Arron ST and Hanahan D Cancer-associated fibroblasts are activated in incipient neoplasia to orchestrate tumor-promoting inflammation in an NF-kappaB-dependent manner. Cancer Cell 17: 135-147, 2010.

7. Sugimoto H, Mundel TM, Kieran MW and Kalluri R: Identification of fibroblast heterogeneity in the tumor microenvironment. Cancer Biol Ther 5: 1640-1646, 2006.

8. Lee KW, Yeo SY, Sung CO and Kim SH: Twist1 is a key regulator of cancer-associated fibroblasts. Cancer Res 75: 73-85, 2015

9. Satoyoshi R, Kuriyama S, Aiba N, Yashiro M and Tanaka M: Asporin activates coordinated invasion of scirrhous gastric cancer and cancer-associated fibroblasts. Oncogene 34: 650-660, 2015.

10. Wang X, Zhou Q, Yu Z, Wu X, Chen X, Li J, Li C, Yan M, Zhu Z, Liu B, et al: Cancer-associated fibroblast-derived Lumican promotes gastric cancer progression via the integrin $\beta 1$-FAK signaling pathway. Int J Cancer 141: 998-1010, 2017.

11. Sugihara $H$, Ishimoto $T$, Yasuda T, Izumi D, Eto K, Sawayama $H$, Miyake K, Kurashige J, Imamura Y, Hiyoshi Y, et al: Cancer-associated fibroblast-derived CXCL12 causes tumor progression in adenocarcinoma of the esophagogastric junction. Med Oncol 32: 618, 2015.

12. Matsumoto $\mathrm{K}$ and Nakamura T: Hepatocyte growth factor and the Met system as a mediator of tumor-stromal interactions. Int J Cancer 119: 477-483, 2006.

13. Kwon Y, Smith BD, Zhou Y, Kaufman MD and Godwin AK: Effective inhibition of c-MET-mediated signaling, growth and migration of ovarian cancer cells is influenced by the ovarian tissue microenvironment. Oncogene 34: 144-153, 2015.

14. Phan LM, Fuentes-Mattei E, Wu W, Velazquez-Torres G, Sircar K, Wood CG, Hai T, Jimenez C, Cote GJ, Ozsari L, et al: Hepatocyte growth factor/cMET pathway activation enhances cancer hallmarks in adrenocortical carcinoma. Cancer Res 75 4131-4142, 2015

15. Grugan KD, Miller CG, Yao Y, Ohashi S, Klein-Szanto AJ, Diehl JA, Herlyn M, Han M, Nakagawa $H$ and Rustgi AK Fibroblast-secreted hepatocyte growth factor plays a functional role in esophageal squamous cell carcinoma invasion. Proc Natl Acad Sci USA 107: 11026-11031, 2010.

16. Jedeszko C, Victor BC, Podgorski I and Sloane BF: Fibroblast hepatocyte growth factor promotes invasion of human mammary ductal carcinoma in situ. Cancer Res 69: 9148-9155, 2009.

17. Wu X, Chen X, Zhou Q, Li P, Yu B, Li J, Qu Y, Yan J, Yu Y, Yan M, et al: Hepatocyte growth factor activates tumor stromal fibroblasts to promote tumorigenesis in gastric cancer. Cancer Lett 335: 128-135, 2013.

18. Jiang J, Liu W, Guo X, Zhang R, Zhi Q, Ji J, Zhang J, Chen X, Li J, Zhang J, et al: IRX1 influences peritoneal spreading and metastasis via inhibiting BDKRB2-dependent neovascularization on gastric cancer. Oncogene 30: 4498-4508, 2011.

19. Carmeliet P and Jain RK: Angiogenesis in cancer and other diseases. Nature 407: 249-257, 2000.

20. Liu J, Huang J, Yao WY, Ben QW, Chen DF, He XY, Li L and Yuan YZ: The origins of vacularization in tumors. Front Biosci 17: 2559-2565, 2012.

21. Zhang J, Qiao L, Liang N, Xie J , Luo H, Deng G and Zhang J: Vasculogenic mimicry and tumor metastasis. JBUON 21: 533-541, 2016
22. Guo Q, Yuan Y, Jin Z, Xu T, Gao Y, Wei H, Li C, Hou W and Hua B: Association between tumor vasculogenic mimicry and the poor prognosis of gastric cancer in China: An updated systematic review and meta-analysis. Biomed Res Int 2016: 2408645, 2016.

23. Folkman J: Can mosaic tumor vessels facilitate molecular diagnosis of cancer? Proc Natl Acad Sci USA 98: 398-400, 2001.

24. di Tomaso E, Capen D, Haskell A, Hart J, Logie JJ, Jain RK, McDonald DM, Jones R and Munn LL: Mosaic tumor vessels: Cellular basis and ultrastructure of focal regions lacking endothelial cell markers. Cancer Res 65: 5740-5749, 2005.

25. Chang YS, di Tomaso E, McDonald DM, Jones R, Jain RK and Munn LL: Mosaic blood vessels in tumors: Frequency of cancer cells in contact with flowing blood. Proc Natl Acad Sci USA 97: 14608-14613, 2000.

26. Xu D, Matsuo Y, Ma J, Koide S, Ochi N, Yasuda A, Funahashi H, Okada Y and Takeyama H: Cancer cell-derived IL-1alpha promotes HGF secretion by stromal cells and enhances metastatic potential in pancreatic cancer cells. J Surg Oncol 102: 469-477, 2010.

27. Lirdprapamongkol K, Chiablaem K, Sila-Asna M, Surarit R, Bunyaratvej A and Svasti J: Exploring stemness gene expression and vasculogenic mimicry capacity in well-and poorly-differentiated hepatocellular carcinoma cell lines. Biochem Biophys Res Commun 422: 429-435, 2012.

28. Zang M, Zhang Y, Zhang B, Hu L, Li J, Fan Z, Wang H, Su L, Zhu Z, Li C, et al: CEACAM6 promotes tumor angiogenesis and vasculogenic mimicry in gastric cancer via FAK signaling. Biochim Biophys Acta 1852: 1020-1028, 2015.

29. Li P, Shan JX, Chen XH, Zhang D, Su LP, Huang XY, Yu BQ, Zhi QM, Li CL, Wang YQ, et al: Epigenetic silencing of microRNA-149 in cancer-associated fibroblasts mediates prostaglandin E2/interleukin-6 signaling in the tumor microenvironment. Cell Res 25: 588-603, 2015.

30. Zhu CC, Chen C, Xu ZQ, Zhao JK, Ou BC, Sun J, Zheng MH, Zong YP and Lu AG: CCR6 promotes tumor angiogenesis via the AKT/NF-kappaB/VEGF pathway in colorectal cancer. Biochim Biophy Acta 1864: 387-397, 2018.

31. Gao LM, Wang F, Zheng Y, Fu ZZ, Zheng L and Chen LL: Roles of fibroblast activation protein and hepatocyte growth factor expressions in angiogenesis and metastasis of gastric cancer. Pathol Oncol Res, 2017.

32. Ma TH, Gao CC, Xie R, Yang XZ, Dai WJ, Zhang JL, Yan W and Wu SN: Predictive values of FAP and HGF for tumor angiogenesis and metastasis in colorectal cancer. Neoplasma 64: 880-886, 2017.

33. Liu X, Wang JH, Li S, Li LL, Huang M, Zhang YH, Liu Y, Yang YT, Ding R and Ke YQ: Histone deacetylase 3 expression correlates with vasculogenic mimicry through the phosphoinositide3-kinase/ERK-MMP-laminin5gamma2 signaling pathway. Cancer Sci 106: 857-866, 2015

34. Chen LX, He YJ, Zhao SZ, Wu JG, Wang JT, Zhu LM, Lin TT, Sun BC and Li XR: Inhibition of tumor growth and vasculogenic mimicry by curcumin through down-regulation of the EphA2/PI3K/MMP pathway in a murine choroidal melanoma model. Cancer Biol Ther 11: 229-235, 2014.

35. Ruf W, Seftor EA, Petrovan RJ, Weiss RM, Gruman LM, Margaryan NV, Seftor RE, Miyagi Y and Hendrix MJ: Differential role of tissue factor pathway inhibitors 1 and 2 in melanoma vasculogenic mimicry. Cancer Res 63: 5381-5389, 2003.

36. Du J, Sun B, Zhao X, Gu Q, Dong X, Mo J, Sun T, Wang J, Sun R and Liu Y: Hypoxia promotes vasculogenic mimicry formation by inducing epithelial-mesenchymal transition in ovarian carcinoma. Gynecol Oncol 133: 575-583, 2014.

37. Liu Q, Qiao L, Liang N, Xie J, Zhang J, Deng G, Luo H and Zhang J: The relationship between vasculogenic mimicry and epithelial-mesenchymal transitions. J Cell Mol Med 20: 1761-1769, 2016.

38. Zhang H, Deng T, Liu R, Bai M, Zhou L, Wang X, Li S, Wang X, Yang $\mathrm{H}$, Li J, et al: Exosome-delivered EGFR regulates liver microenvironment to promote gastric cancer liver metastasis. Nat Commun 8: 15016, 2017

39. Hao NB, Tang B, Wang GZ, Xie R, Hu CJ, Wang SM, Wu YY, Liu E, Xie X and Yang SM: Hepatocyte growth factor (HGF) upregulates heparanase expression via the PI3K/Akt/NF- $\kappa \mathrm{B}$ signaling pathway for gastric cancer metastasis. Cancer Lett 361: 57-66, 2015.

40. Hanahan D and Weinberg RA: Hallmarks of cancer: The next generation. Cell 144: 646-674, 2011. 
41. Borcoman E and Le Tourneau C: Pembrolizumab in cervical cancer: Latest evidence and clinical usefulness. Ther Adv Med Oncol 9: 431-439, 2017.

42. Fuchs CS, Marshall J and Barrueco J: Randomized, controlled trial of irinotecan plus infusional, bolus, or oral fluoropyrimidines in first-line treatment of metastatic colorectal cancer: Updated results from the BICC-C study. J Clin Oncol 26: 689-690, 2008.

43. Ye W: The Complexity of translating anti-angiogenesis therapy from basic science to the clinic. Dev Cell 37: 114-125, 2016.

44. Zhang S, Zhang D and Sun B: Vasculogenic mimicry: Current status and future prospects. Cancer Lett 254: 157-164, 2007.

45. Jin J, Yuan F, Shen MQ, Feng YF and He QL: Vascular endothelial growth factor regulates primate choroid-retinal endothelial cell proliferation and tube formation through PI3K/Akt and MEK/ERK dependent signaling. Mol Cell Biochem 381: 267-272, 2013.
46. Kim GD: Kaempferol inhibits angiogenesis by suppressing HIF-1 $\alpha$ and VEGFR2 activation via ERK/p38 MAPK and PI3K/Akt/mTOR signaling pathways in endothelial cells. Prev Nutr Food Sci 22: 320-326, 2017.

47. Huang B, Xiao E and Huang M: MEK/ERK pathway is positively involved in hypoxia-induced vasculogenic mimicry formation in hepatocellular carcinoma which is regulated negatively by protein kinase A. Med Oncol 32: 408, 2015.

48. Chiablaem K, Lirdprapamongkol K, Keeratichamroen S, Surarit R and Svasti J: Curcumin suppresses vasculogenic mimicry capacity of hepatocellular carcinoma cells through STAT3 and PI3K/AKT inhibition. Anticancer Res 34: 1857-1864, 2014.

49. Williamson SC, Metcalf RL, Trapani F, Mohan S, Antonello J, Abbott B, Leong HS, Chester CPE, Simms N, Polanski R, et al: Vasculogenic mimicry in small cell lung cancer. Nat Commun 7 : 13322, 2016. 